\section{Extensive post-transcriptional regulation of microRNAs and its implications for cancer}

\author{
J. Michael Thomson, ${ }^{1}$ Martin Newman, ${ }^{1}$ \\ Joel S. Parker, ${ }^{4}$ Elizabeth M. Morin-Kensicki, ${ }^{1}$ \\ Tricia Wright, ${ }^{2}$ and Scott $M$. Hammond ${ }^{1,3,5}$
}

${ }^{1}$ Department of Cell and Developmental Biology, University of North Carolina, Chapel Hill, North Carolina 27599, USA; ${ }^{2}$ Curriculum in Genetics and Molecular Biology, University of North Carolina, Chapel Hill, North Carolina 27599, USA; ${ }^{3}$ Lineberger Comprehensive Cancer Center, University of North Carolina, Chapel Hill, North Carolina 27599, USA; ${ }^{4}$ Constella Group, Durham, North Carolina 27713, USA

MicroRNAs (miRNAs) are short, noncoding RNAs that post-transcriptionally regulate gene expression. While hundreds of mammalian miRNA genes have been identified, little is known about the pathways that regulate the production of active miRNA species. Here we show that a large fraction of miRNA genes are regulated posttranscriptionally. During early mouse development, many miRNA primary transcripts, including the Let-7 family, are present at high levels but are not processed by the enzyme Drosha. An analysis of gene expression in primary tumors indicates that the widespread downregulation of miRNAs observed in cancer is due to a failure at the Drosha processing step. These data uncover a novel regulatory step in miRNA function and provide a mechanism for miRNA down-regulation in cancer.

Supplemental material is available at http://www.genesdev.org.

Received April 27, 2006; revised version accepted June 14, 2006.

The founding microRNA (miRNA), lin-4, was discovered more than 20 years ago in the nematode Caenorhabditis elegans (Lee et al. 1993). Elegant studies demonstrated that the gene product of $7 i n-4$ was a noncoding RNA that post-transcriptionally regulated several critical genes during development (Wightman et al. 1993). More recently, a large number of miRNA genes have been identified in plant and animal genomes. To date, >300 miRNAs have been validated in the human genome, and computational predictions suggest that many hundreds more exist (Aravin and Tuschl 2005). While it is clear that these small, noncoding RNAs have essential functions in mammalian biology, few miRNA genes have been functionally linked to specific cellular pathways. For example, miR-181 modulates hematopoietic differentiation, and miR-1 and miR-133 participate in skeletal and cardiac muscle development. The polycistronic cluster miR-17 92 promotes lymphomagenesis, while Let-7

[Keywords: miRNA; microRNA; let-7; RISC; Drosha; cancer]

${ }^{5}$ Corresponding author.

E-MAIL hammond@med.unc.edu; FAX (919) 966-1856.

Article published online ahead of print. Article and publication date are online at http://www.genesdev.org/cgi/doi/10.1101/gad.1444406. suppresses proliferation by targeting the oncogene Ras (for review, see Wienholds and Plasterk 2005).

For most miRNA genes, however, biological information is limited to expression analyses. In mouse and zebrafish, few miRNAs are expressed in early embryos (Thomson et al. 2004; Wienholds et al. 2005). During mid- to late embryonic development, large numbers of miRNAs are induced in temporal and spatial patterns (Kloosterman et al. 2006). This culminates in adult tissues, where a large fraction of the known miRNA genes are expressed. Interestingly, most of these same miRNA genes are down-regulated in cancer, perhaps reflecting a loss of cellular differentiation (Takamizawa et al. 2004; Lu et al. 2005). The regulatory mechanism behind these expression changes is largely unknown, although the most obvious candidate is transcriptional control. It is difficult, however, to reconcile this model with the widespread, parallel reduction in miRNA expression observed in most types of human cancer.

A second possibility is that miRNA maturation is a regulated event. The biogenesis of miRNAs begins with a primary transcript, termed the pri-miRNA, which is generated by RNA polymerase II (for review, see Kim 2005). The active species is contained in a stem-loop structure that is liberated by the nuclear ribonuclease III (RNase III) Drosha. This stem-loop, termed the premiRNA or precursor, is exported from the nucleus in a Ran/GTP/Exportin 5-mediated event. In the cytoplasm, the precursor is further processed by the RNase III enzyme Dicer to generate the mature miRNA species. In a concerted reaction, this siRNA-like product is loaded into the RNA induced silencing complex (RISC), where it mediates target mRNA translational suppression (Du and Zamore 2005; Gregory et al. 2005; Maniataki and Mourelatos 2005).

In principle, any step during this maturation process could be regulated. The core enzymes are widely expressed, however, and no post-translational regulation of Drosha or Dicer has been reported. Discrepancies between the levels of primary transcript, precursor, and mature miRNA species have been reported; however, no clear model is apparent (Suh et al. 2004; Eis et al. 2005). Here we report that a large fraction of miRNAs is regulated during the Drosha processing step, and this regulation has a major impact on miRNA expression during embryonic development and in cancer.

\section{Results and Discussion}

A striking event during mouse development is the massive induction of Let-7 family miRNAs at $\sim 10.5 \mathrm{~d}$ of gestation. This is exemplified by Let-7g. This miRNA is housed in the second intron of the WD-40 repeat gene AK037620 (Fig. 1A). Processing of this primary transcript by Drosha yields a 79-nt stem-loop precursor. Further processing by Dicer leads to the 21-nt mature species. We analyzed the expression of all three molecular forms by Northern blotting (Fig. 1B). As previously reported, mature Let-7g is undetectable in embryonic stem (ES) cells and P19 embryonal teratocarcinoma cells (Thomson et al. 2004). Expression is detectable at 10.5 d gestation and is high at $14.5 \mathrm{~d}$. The precursor is detectable slightly earlier than the mature miRNA, suggesting a delay at the Dicer processing step. Similar results have 
A

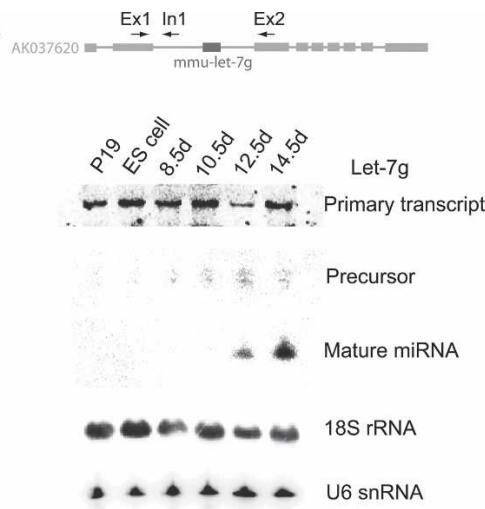

C

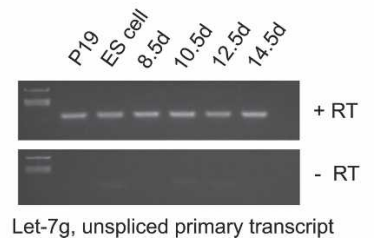

D

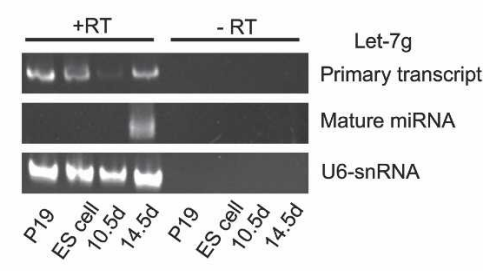

E

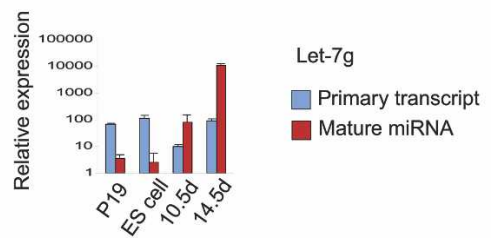

Figure 1. Expression of let-7g during mouse development. (A) The genomic organization of Let-7g is shown. RT-PCR primer sites are indicated by arrows. Primers Ex1 and Ex2 were used for PCR of the primary transcript. Primers Ex1 and In1 were used for PCR of the unspliced primary transcript. (B) Northern blot analysis of the molecular species of Let-7g. 18S rRNA and U6 snRNA were used for loading controls for pri-miRNA and pre-miRNA/mature, respectively. (C) Nonquantitative RT-PCR of the unspliced primary transcript. Control reactions without the reverse transcription step are shown. $(D)$ Nonquantitative RT-PCR of the let-7g primary transcript and mature species. The U6-snRNA reference is also shown. The right lanes are control reactions without reverse transcription step. $(E)$ Real-time RT-PCR analysis of the let-7g primary transcript and mature species. Reactions were performed in triplicate and normalized to U6 cycle threshold values. Expression is shown as relative values on a logarithmic scale.

been observed in mouse and Drosophila development (Hutvagner et al. 2001; Schulman et al. 2005). Surprisingly, the primary transcript is highly expressed throughout development, with little difference in expression between ES cells and 14.5-d embryos. This discrepancy is not resolved by the amount of unspliced pri-miRNA, since this is also essentially constant (Fig. 1C).

We next quantitated the levels of primary and mature species by real-time RT-PCR. We adapted a published procedure to measure the amount of both species from a single RT reaction (see Supplemental Figs. 1, 2 for validation; Fig. 1D illustrates a nonquantitative example; Shi and Chiang 2005). U6 snRNA was used for normalization for mature and primary species. This RNA exhibited more consistent expression during embryonic development than more typical reference RNAs such as $\beta$-2 microglobulin, glyceraldehyde-3-phosphate dehydrogenase, and $\beta$-glucuronidase. Using this procedure, we determined that the amount of mature Let-7g increases 4200-fold between ES cells and 14.5-d embryos. As observed by Northern blot analysis, expression levels of the primary transcript do not match the mature miRNA but are relatively constant (Fig. 1E, note log scale).

There are several possible explanations for the different expression levels of the pri-miRNA and the mature miRNA. There could be rapid turnover of the mature species in ES cells compared to late embryos. This is unlikely, since mature miRNAs from other gene families are present in ES cells (e.g., miR-290 295), and published data suggest that all miRNAs are loaded into RISC complexes nondiscriminately (Liu et al. 2004). A second possibility is that the precursor for Let-7g is retained in the nucleus or otherwise made inaccessible to Dicer. In that circumstance, we would expect to see an accumulation of precursor. Our data disagree with this, since the precursor is essentially undetectable in ES cells. A third possibility, most congruous with our data, is that processing of Let-7g is blocked at the Drosha step. Release of the block would enable production of mature Let-7g. It is worth emphasizing that this is not simply a delay in processing during development, but a complete block. ES cells are grown continuously in culture, express high levels of Let-7g primary transcript, and never process a significant quantity to the precursor or mature species.

We next investigated processing of other miRNA genes that are expressed during development (Fig. 2). Let-7 family miRNAs are located at eight genomic loci (Griffiths-Jones et al. 2006). Of these we were able to detect primary transcripts for four loci. Notable is the Let-7f-2/miR-98 cistron, which is located within an intron of the widely expressed ubiquitin ligase gene HUWE-1. All four primary transcripts were expressed at similar levels throughout development. Similar to Let-7g, all mature miRNAs within these genes were elevated several thousandfold between ES cells and $14.5 \mathrm{~d}$ of gestation. The correlation between primary transcript expression and mature miRNA expression was close to zero, with the exception of Let-7i (see Table 1). For this miRNA, the primary transcript is induced during development, although there is still a large difference in processing efficiency (300-fold) (Table 1). Two of the four Let-7 clusters we analyzed were intronic, and two were exonic. Thus there is no correlation between regulated processing by Drosha and intron/exon location.

This Drosha regulatory step has not been observed in other organisms. C. elegans let-7, for example, is induced at the fourth larval stage and continues into the adult. Expression is controlled by defined enhancer elements in the promoter of the primary transcript (Johnson et al. 2003). Expression of the primary transcript is closely correlated with mature let-7 (Bracht et al. 2004).

The developmental function of Let-7 family members in mammals is not known. There have been reports of decreased Let-7 expression in primary tumors (Takamizawa et al. 2004; Lu et al. 2005). This may have functional consequences. The oncogene Ras is a validated target of Let-7 (Johnson et al. 2005). Thus, decreased Let-7 expression would lead to increased Ras expression, which would promote survival of tumor cells. Our data raise the possibility that Let-7 down-regulation in tumors is post-transcriptional (see below).

Several other families of miRNAs are up-regulated during mouse development. We were able to detect pri- 

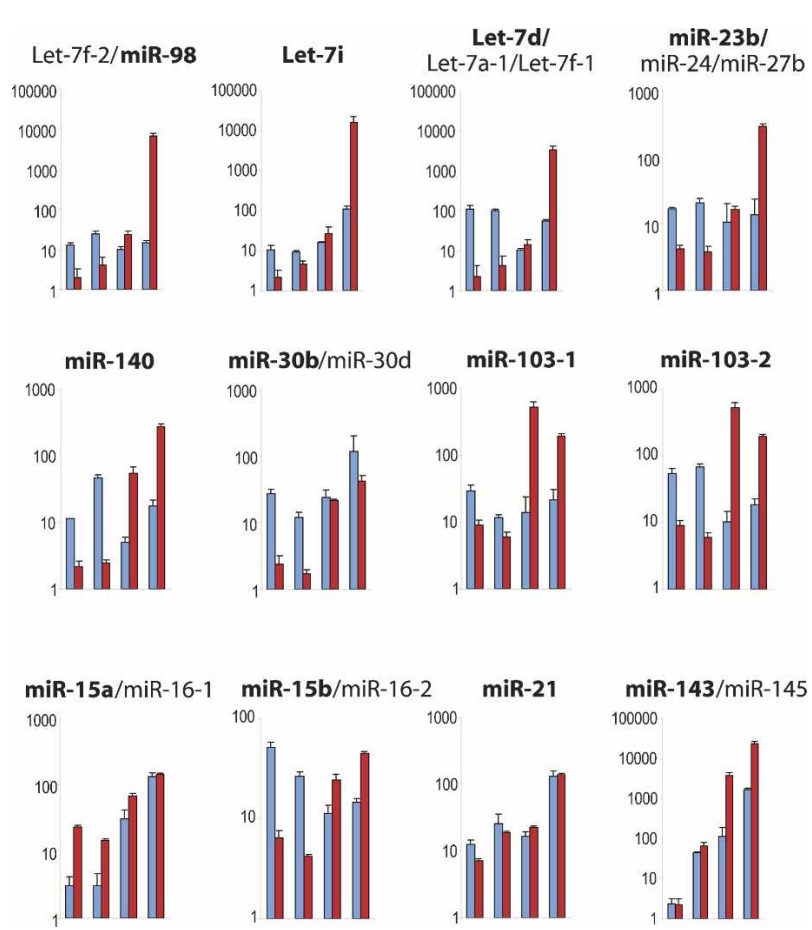

Figure 2. miRNA expression during mouse development. The expression levels of primary transcript and mature species from 12 representative miRNAs are shown. Red bars represent mature miRNA, and blue bars represent primary transcript. All analyses are performed with the following RNA samples, from left to right: P19 teratocarcinoma cell line; embryonic stem cell line; 10.5-d gestation mouse embryo; 14.5 -d gestation mouse embryo. Reactions were performed in triplicate and normalized to U6 cycle threshold values. Expression is shown as relative values on a logarithmic scale. The bold font indicates the mature miRNA gene that was used for RTPCR analysis. In all cases, these are unique miRNA sequences in the mouse genome.

mary transcripts for nine of these miRNAs. Most cases exhibited regulated Drosha processing (Fig. 2; Table 1). Exceptions were miR-21 and the miR-143/miR-145 cluster. Both primary transcripts matched expression of the mature species (correlation $=1.0$ and 0.99 , respectively). Another interesting example is the $\mathrm{miR}-15 / \mathrm{miR}-16$ cistron, which is located at two genomic loci. Each primary transcript displays distinct expression kinetics. The Chromosome 14 copy is located within an uncharacterized gene that is induced during development. The Chromosome 3 copy, in contrast, is located within the condensin subunit SMC4L1, which is constitutively expressed. Thus, each pri-miRNA contributes to the mature species in a complex manner, with a post-transcriptionally regulated component (Chromosome 3) and a transcriptionally regulated component (Chromosome $14)$.

It should be noted that coordinate expression of the primary transcript and the mature miRNA does not prove that Drosha processing is not regulated. Such miRNAs (Table 1, bottom panel) may be regulated at transcription and Drosha processing. It remains a possibility that all miRNAs are regulated at the Drosha step, except for miRNAs that have demonstrated expression in the early mouse embryo. Interestingly, this has implications for experiments that use ectopic expression of miRNAs in ES cells. We predict that this would fail to
Table 1. Expression correlation for mature/pri-miRNA pairs

\begin{tabular}{lcc}
\hline \multicolumn{1}{c}{ miRNA gene } & $\begin{array}{c}\text { pri-miRNA/ } \\
\text { mature } \\
\text { correlation }\end{array}$ & $\begin{array}{c}\Delta \text { processing } \\
\text { efficiency }\end{array}$ \\
\hline let-7g & +0.29 & 5400 \\
let-7f-2/miR-98 & -0.12 & 2700 \\
let-7i & +1.00 & 300 \\
let-7d/let-7a-1/let-7f-1 & -0.21 & 1400 \\
miR-140 & -0.20 & 290 \\
miR-23b/miR-24-2/miR-27b & -0.29 & 110 \\
miR-30/b/miR-30d & +0.89 & 2.5 \\
miR-103-1 & -0.38 & 18 \\
miR-103-2 & -0.87 & 120 \\
miR-15b/miR-16-2 & -0.68 & 19 \\
miR-15a/miR-16-1 & & \\
miR-21 & +0.98 & 0.23 \\
miR-143/miR-145 & +0.99 & 1.4 \\
& +0.99 & 9.3
\end{tabular}

Pearson correlations were calculated for each mature miRNA/ pri-miRNA pair and are shown in the middle column. The change in processing efficiency is defined as the ratio of mature to pri-miRNA in a 14.5-d embryo divided by the ratio of mature to pri-miRNA in ES cells, and is shown in the right column. The table is divided into miRNAs regulated by Drosha (top) and miRNAs potentially unregulated by Drosha (bottom).

produce the mature species, unless cis-regulatory elements were removed from the expression cassette.

Our data suggest that the differentiation events that occur during embryonic development activate Drosha processing of specific miRNAs. To directly test this we used the teratocarcinoma cell line P19, which can be differentiated in culture into multiple cell types (Rudnicki et al. 1990). miRNA microarray expression analysis of untreated and differentiated P19 cells mirrors the expression changes observed during mouse development (data not shown). Embryonic miRNAs, such as the miR-290 295 cluster, are down-regulated during differentiation. In contrast, miRNAs that are up-regulated during mouse development, including Let-7 family members, are increased upon differentiation. As in embryonic development, the increases in Let-7 miRNAs are not coupled to transcription of the pri-miRNA (see Fig. 3).
Let-7f-2/miR-98

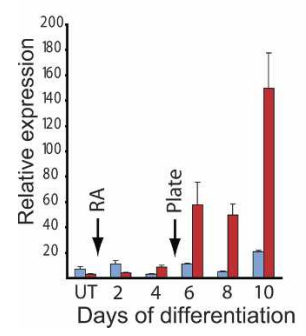

Let-7g

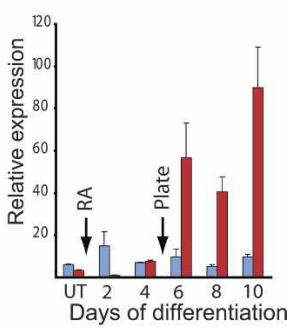

Figure 3. miRNA expression during P19 cell differentiation. P19 teratocarcinoma cells were differentiated by forming embryoid bodies for $4 \mathrm{~d}$ in the presence of all-trans retinoic acid (RA), followed by plating without RA. Arrows indicate RA treatment and plating time. Primary transcript and mature miRNA species were quantitated by real-time RT-PCR. Reactions were performed in triplicate and normalized to U6 cycle threshold values. Expression is shown as relative values on a linear scale. Red bars indicate mature miRNA, and blue bars indicate pri-miRNA. 
One experimental observation of cancer cells is the widespread alterations in miRNA expression. While some miRNAs are elevated, for example, the oncogenic cluster miR-17 92, most miRNAs have significantly reduced expression (He et al. 2005; Lu et al. 2005). Our data raise the possibility that these reductions are a consequence of the Drosha processing block. To address this, we analyzed existing expression data, comparing mature miRNA levels with the primary transcript. The most complete data set, from the Broad Institute, has Affymetrix mRNA expression data and Luminex miRNA data from a wide range of primary tumors and normal tissues (Ramaswamy et al. 2001; Lu et al. 2005). We combined the data set in the following manner: 68 tumors and 21 normal tissue samples had data for miRNA and mRNA expression. Of 217 miRNAs, 22 could be mapped to a primary transcript that was present on the Affymetrix microarray. When this restricted miRNA data set was hierarchically clustered, the normal samples were located in a single node with some tumor samples, while most tumors clustered in a separate node (Fig. 4A). The tumor samples had overall reduction in miRNA expression levels. This was qualitatively similar to the entire miRNA expression map, as previously published (Lu et al. 2005).

We then created an expression map of primary transcript expression levels (Fig. 4A). The samples and genes are arranged in the same order as for the miRNA expression map. The high and low clusters of expression are completely lost in the primary transcript expression map. We performed correlation analysis between each mature/pri-miRNA expression pair, for each sample. The data are represented in the histogram in Figure 4B. There is no correlation between primiRNA and mature expression in the tumor samples, while the normal tissue samples had positive correlation (KS test, $p<0.01$ ). This demonstrates that the miRNA alterations that occur in tumors, for this limited set of genes, are not due to misregulated transcription.

Our data suggest a multistep model for the control of miRNA expression. Transcription of the pri-miRNA can be regulated, as has been demonstrated for tissue-specific miRNAs (Fazi et al. 2005; O'Donnell et al. 2005; Zhao et al. 2005; Chen et al. 2006). Processing at the Dicer step can be delayed or inhibited (Hutvagner et al. 2001; Schulman et al. 2005; Obernosterer et al. 2006). We demonstrate that further suppression of miRNA production is achieved at the Drosha step. This may be necessary for early development, where inappropriate expression of even small amounts of Let-7 may promote differentiation, with disastrous conse- quences. This model also allows miRNAs to be located in essential housekeeping genes that are ubiquitously expressed.

The biochemical nature of Drosha regulation is unknown. We measured the expression levels of Drosha and its binding partner DGCR8, during the P19 differentiation time course (Supplemental Fig. 3). No induction occurred concordant with the production of mature miRNAs. It is possible these proteins are regulated by post-translational modification. Alternatively, additional regulatory binding proteins may be required for specific miRNA processing. Recently, adensosine deaminase (ADAR) editing of specific pri-miRNAs has been reported (Yang et al. 2006). This editing event leads to decreased processing of the miRNA by Drosha and increased turnover by the Tudor-SN nuclease. We tested whether this mechanism is responsible for the Drosha block during embryogenesis. We failed to find evidence of A-I editing of Let-7 pri-miRNAs in ES cells (data not shown). Our data do not, however, discount the possibil-
A

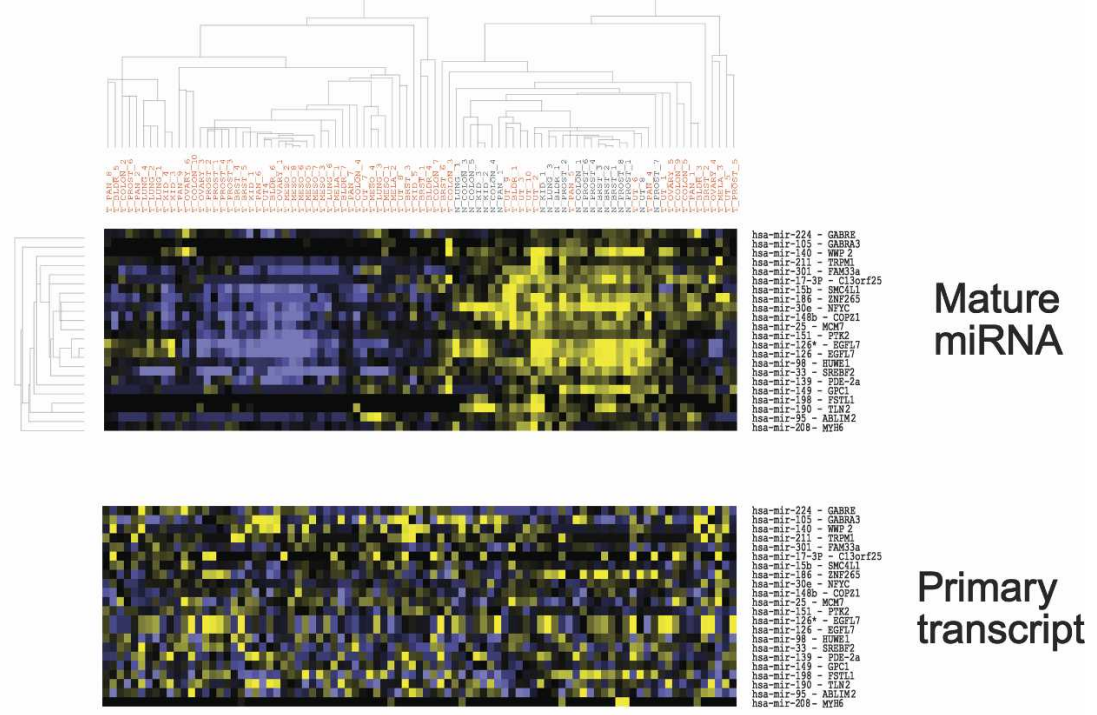

B

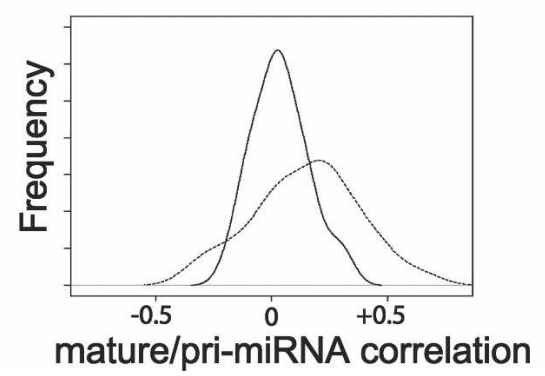

Figure 4. miRNA expression in primary tumors. (A) Normalized miRNA expression data from Lu et al. (2005) were clustered hierarchically in both dimensions and are displayed as an expression map. Yellow indicates increased expression, and blue indicates decreased expression, relative to the median. Primary transcript expression data from Ramaswamy et al. (2001) were mapped in the same order as the mature miRNA expression map. Mature miRNA/ primary transcript gene pairs are indicated on the right. Tumor samples are indicated in red, and normal tissues are indicated in black. $(B)$ Pearson correlation values for each mature/primiRNA value pair were calculated. Values for normal samples (dashed line) and tumor samples (solid line) are plotted as a histogram. 
ity of other structural changes in the pri-miRNA that block processing. An alternative mechanism is the sequestration of regulated pri-miRNAs away from the processing apparatus. The exact nature of the regulatory mechanism awaits further investigation.

\section{Materials and methods}

Cell lines

The feederless ES cell line E14Tg2A.4 was grown on gelatin-coated plates in Glasgow MEM (Sigma) supplemented with $2 \mathrm{mM}$ glutamine, $1 \mathrm{mM}$ pyruvate, $1 \times$ nonessential amino acids, $15 \%$ fetal bovine serum $(\mathrm{Hy}-$ clone), $0.1 \mathrm{mM} \beta$-mercaptoethanol, and $10^{3}$ units $/ \mathrm{mL}$ leukocyte inhibitory factor (Chemicon). The P19 teratocarcinoma cell line was grown in DMEM (Sigma) supplemented with $7.5 \%$ calf serum (Hyclone) and $2.5 \%$ fetal bovine serum. P19 cells were differentiated as follows: Cells were seeded on nonadhesive plates in $\alpha$-MEM (Sigma) supplemented with 5\% fetal bovine serum and $500 \mathrm{nM}$ all-trans retinoic acid (Sigma). After $4 \mathrm{~d}$, the aggregated cells were plated on standard tissue culture dishes in DMEM supplemented with $7.5 \%$ calf serum and $2.5 \%$ fetal bovine serum, and grown for the indicated number of days.

\section{RNA isolation}

Dissected whole embryos from pregnant CD1 mice were flash-frozen in liquid nitrogen and pulverized into powder. Total RNA was extracted from pooled embryos of two to eight embryos or from cell lines with Trizol Reagent (Invitrogen) according to the manufacturer's instructions.

Northern blot analysis of mRNA

Five micrograms of total RNA was resolved on a $1 \%$ agarose formaldehyde gel and transferred overnight to a positively charged nylon membrane by capillary transfer with $10 \times$ SSC. The membrane was washed briefly in $2 \times$ SSC, dried, and UV cross-linked, and incubated overnight with $10^{7} \mathrm{cpm}$ of a random-primed probe directed against the mouse Let$7 \mathrm{~g}$ primary transcript in Church and Gilbert high-stringency buffer. PCR primers specific for the mouse Let-7g primary transcript (let-7g-probe-F, 5'-TTTAGTCCCAATGGCGAGAC-3'; let-7g-probe-R, 5'-CATCACCA CACCCTTGAATG-3') were used to make the probe. The membrane was washed once for $15 \mathrm{~min}$ at $42^{\circ} \mathrm{C}$ in $2 \times \mathrm{SSC}, 0.1 \%$ SDS and then twice for $15 \mathrm{~min}$ at $65^{\circ} \mathrm{C}$ in $0.2 \times \mathrm{SSC}, 0.1 \%$ SDS. PhosphorImaging using the Storm system (Molecular Dynamics) revealed the Let-7g primary transcript. The size of pri-Let- $7 \mathrm{~g}(3.7 \mathrm{~kb})$ was confirmed against $18 \mathrm{~S}$ and $28 \mathrm{~S}$ rRNA markers. The size of pre-Let-7g was confirmed against an in vitro transcribed pre-Let-7g RNA. All primers were purchased from MWG Biotech.

Northern blot analysis of pre-miRNA and mature miRNA

Five micrograms of total RNA was resolved on $15 \%$ (mature) or $7.5 \%$ (precursor) acrylamide- $8 \mathrm{M}$ urea-TAE gels as described previously (Hammond et al. 2000). After electroblotting to Hybond N+ membranes, blots were probed with an end-labeled Locked Nucleic Acid (LNA) probe AC $\mathrm{TgTaCaAaCtAcTaCcTcA}$ (small letters are LNA; caps are DNA). Hybridization was performed in Church and Gilbert high-stringency buffer at $65^{\circ} \mathrm{C}$, followed by three washes in $0.1 \times \operatorname{SSC}$ at $65^{\circ} \mathrm{C}$.

\section{Quantitative RT-PCR}

Total RNA $(20 \mathrm{\mu g}$ ) was DNase I (Promega) treated according to the manufacturer's instructions, phenol:chloroform extracted, ethanol precipitated, and dissolved in DEPC-treated $\mathrm{dH}_{2} \mathrm{O}$. RNA $(10 \mu \mathrm{g})$ was polyadenylated using Poly(A) polymerase (Ambion) according to the manufacturer's instructions, phenol:chloroform extracted, ethanol-precipitated, and dissolved in DEPC-treated $\mathrm{dH}_{2} \mathrm{O}$. A modified cDNA was made as follows: $10 \mu \mathrm{g}$ of polyadenylated RNA was reverse-transcribed using Superscript II reverse transcriptase (Invitrogen) with $2.5 \mu \mathrm{g}$ of random hexamers and $500 \mathrm{ng}$ of oligo(dT) adapter primer (5'-GCGAGCACAG AATTAATACGACTCACTATAGGTTTTTTTTTTTTVN-3') according to the manufacturer's instructions. The reaction was terminated by incubation at $70^{\circ} \mathrm{C}$ for $10 \mathrm{~min}$ and diluted into $2 \mathrm{~mL}$ of $\mathrm{dH}_{2} \mathrm{O}(5 \mu \mathrm{g} / \mathrm{mL})$. Quantitative PCR was used to measure both the mature miRNA and the host mRNA transcript as follows: $5 \mu \mathrm{L}$ of cDNA was mixed with 5 pmol of both the forward and reverse primers in a final volume of $12.5 \mu \mathrm{L}$ and mixed with $12.5 \mu \mathrm{L}$ of $2 \times$ SYBR Green PCR master mix (Applied Biosys- tems). Primer sequences and other pri-miRNA information are in Supplemental Table 1. All reactions were run in triplicate on a DNA Engine Opticon 2 (MJ Research) using two amplification protocols. A standard protocol was performed for the pri-miRNA PCR, $20 \mathrm{sec}$ at $94^{\circ} \mathrm{C}, 30 \mathrm{sec}$ at $59^{\circ} \mathrm{C}$, and $20 \mathrm{sec}$ at $72^{\circ} \mathrm{C}$ for 40 cycles. Mature miRNA PCR was performed according to the high-stringency protocol of Shi and Chiang (2005) except the reverse primer Mir-qPCR-3-3' (5'-GCGAGCA CAGAATTAATACGACTCAC-3') was used in conjunction with an exact sequence-specific primer to each miRNA. Mature and pri-miRNA expression both used the reference gene U6 snRNA (U6-F, 5'-CGCTTC GGCAGCACATATAC-3'; U6-R, 5'-TTCACGAATTTGCGTGTCAT$\left.3^{\prime}\right)$. Expression was calculated using the formula $2^{-\Delta C_{T}}$ with $\Delta C_{T}=\left(C_{T}\right.$ miRNA $-C_{T}$ reference RNA $)$ for mature miRNA or $\Delta C_{T}=\left(C_{T}\right.$ primiRNA $-C_{T}$ reference RNA) for pri-miRNA. Nonquantitative PCR conditions for the Let-7g pri-miRNA and mature miRNA, and U6 reference gene were as mentioned above, except the cycle numbers were 40,35 , and 30, respectively. The same conditions were performed on an equal amount of DNase I-treated RNA as a negative control. Reactions $(5 \mu \mathrm{L})$ were resolved by electrophoresis on $12 \%$ native polyacrylamide TBE gels and stained with ethidium bromide. Unspliced pri-miRNA was analyzed by RT-PCR at 50 cycles. The same conditions were performed on an equal amount of DNase I-treated RNA as a negative control. For analysis of Drosha, DGCR-8, and Oct-4, qRT-PCR was performed similarly, using b2-macroglobulin as a reference RNA.

\section{Microarray gene expression analysis}

Normalized, log-transformed expression data were downloaded from http://www.broad.mit.edu/cgi-bin/cancer/datasets.cgi. Eighty-nine samples were common to the miRNA and mRNA data sets. Twenty-two miRNA/ pri-miRNA pairs were found in the combined data sets. This reduced set of miRNA data was median-centered by gene and hierarchically clustered in both dimensions using Cluster software (Stanford University). An expression map was generated using Treeview software (Stanford University). The pri-miRNA data set was arranged in the same order as the miRNA clustered data and median-centered by gene, and a nonclustered expression map was generated. The Pearson correlation of normalized, log-transformed intensities was calculated for each mature/primiRNA pair. Pairwise correlations were tabulated across tumor or normal samples, and a smoothed histogram was generated.

\section{Acknowledgments}

We thank James Tsuruta and Deborah O'Brien for use of the qPCR system. We thank Clark Jeffries and members of the Hammond lab for discussions and critical reading of the manuscript. This research was funded by grants from the National Institutes of Health and General Motors Cancer Research Foundation (to S.M.H.) and from the American Cancer Society (to J.M.T.).

\section{References}

Aravin, A. and Tuschl, T. 2005. Identification and characterization of small RNAs involved in RNA silencing. FEBS Lett. 579: 5830-5840.

Bracht, J., Hunter, S., Eachus, R., Weeks, P., and Pasquinelli, A.E. 2004. Trans-splicing and polyadenylation of let-7 microRNA primary transcripts. RNA 10: 1586-1594.

Chen, J.F., Mandel, E.M., Thomson, J.M., Wu, Q., Callis, T.E., Hammond, S.M., Conlon, F.L., and Wang, D.Z. 2006. The role of microRNA-1 and microRNA-133 in skeletal muscle proliferation and differentiation. Nat. Genet. 38: 228-233.

$\mathrm{Du}, \mathrm{T}$. and Zamore, P.D. 2005. microPrimer: The biogenesis and function of microRNA. Development 132: 4645-4652.

Eis, P.S., Tam, W., Sun, L., Chadburn, A., Li, Z., Gomez, M.F., Lund, E., and Dahlberg, J.E. 2005. Accumulation of miR-155 and BIC RNA in human B cell lymphomas. Proc. Nat1. Acad. Sci. 102: 3627-3632.

Fazi, F., Rosa, A., Fatica, A., Gelmetti, V., De Marchis, M.L., Nervi, C., and Bozzoni, I. 2005. A minicircuitry comprised of microRNA-223 and transcription factors NFI-A and C/EBP $\alpha$ regulates human granulopoiesis. Cell 123: 819-831.

Gregory, R.I., Chendrimada, T.P., Cooch, N., and Shiekhattar, R. 2005. Human RISC couples microRNA biogenesis and posttranscriptional gene silencing. Cell 123: 631-640.

Griffiths-Jones, S., Grocock, R.J., van Dongen, S., Bateman, A., and En- 
right, A.J. 2006. miRBase: microRNA sequences, targets and gene nomenclature. Nucleic Acids Res. 34 (Database issue): D140-D144.

Hammond, S.M., Bernstein, E., Beach, D., and Hannon, G.J. 2000. An RNA-directed nuclease mediates post-transcriptional gene silencing in Drosophila cells. Nature 404: 293-296.

He, L., Thomson, J.M., Hemann, M.T., Hernando-Monge, E., Mu, D., Goodson, S., Powers, S., Cordon-Cardo, C., Lowe, S.W., Hannon, G.J., et al. 2005. A microRNA polycistron as a potential human oncogene. Nature 435: 828-833.

Hutvagner, G., McLachlan, J., Pasquinelli, A.E., Balint, E., Tuschl, T., and Zamore, P.D. 2001. A cellular function for the RNA-interference enzyme Dicer in the maturation of the let-7 small temporal RNA. Science 293: 834-838.

Johnson, S.M., Lin, S.Y., and Slack, F.J. 2003. The time of appearance of the C. elegans let-7 microRNA is transcriptionally controlled utilizing a temporal regulatory element in its promoter. Dev. Biol. 259: 364-379.

Johnson, S.M., Grosshans, H., Shingara, J., Byrom, M., Jarvis, R., Cheng, A., Labourier, E., Reinert, K.L., Brown, D., and Slack, F.J. 2005. RAS is regulated by the let-7 microRNA family. Cell 120: 635-647.

Kim, V.N. 2005. MicroRNA biogenesis: Coordinated cropping and dicing. Nat. Rev. Mol. Cell Biol. 6: 376-385.

Kloosterman, W.P., Wienholds, E., de Bruijn, E., Kauppinen, S., and Plasterk, R.H. 2006. In situ detection of miRNAs in animal embryos using LNA-modified oligonucleotide probes. Nat. Methods 3: 27-29.

Lee, R.C., Feinbaum, R.L., and Ambros, V. 1993. The C. elegans heterochronic gene lin-4 encodes small RNAs with antisense complementarity to lin-14. Cell 75: 843-854.

Liu, J., Carmell, M.A., Rivas, F.V., Marsden, C.G., Thomson, J.M., Song, J.J., Hammond, S.M., Joshua-Tor, L., and Hannon, G.J. 2004. Argonaute2 is the catalytic engine of mammalian RNAi. Science 305: 1437-1441.

Lu, J., Getz, G., Miska, E.A., Alvarez-Saavedra, E., Lamb, J., Peck, D., Sweet-Cordero, A., Ebert, B.L., Mak, R.H., Ferrando, A.A., et al. 2005. MicroRNA expression profiles classify human cancers. Nature 435: 834-838.

Maniataki, E. and Mourelatos, Z. 2005. A human, ATP-independent, RISC assembly machine fueled by pre-miRNA. Genes \& Dev. 19: 2979-2990.

Obernosterer, G., Leuschner, P.J.F., Alenius, M., and Martinez, J. 2006. Post-transcriptional regulation of microRNA expression. RNA 12: $1161-1167$

O'Donnell, K.A., Wentzel, E.A., Zeller, K.I., Dang, C.V., and Mendell, J.T 2005. c-Myc-regulated microRNAs modulate E2F1 expression. $\mathrm{Na}$ ture 435: 839-843.

Ramaswamy, S., Tamayo, P., Rifkin, R., Mukherjee, S., Yeang, C.H., Angelo, M., Ladd, C., Reich, M., Latulippe, E., Mesirov, J.P., et al 2001. Multiclass cancer diagnosis using tumor gene expression signatures. Proc. Nat1. Acad. Sci. 98: 15149-15154.

Rudnicki, M.A., Sawtell, N.M., Reuhl, K.R., Berg, R., Craig, J.C., Jardine, K., Lessard, J.L., and McBurney, M.W. 1990. Smooth muscle actin expression during P19 embryonal carcinoma differentiation in cell culture. J. Cell. Physiol. 142: 89-98.

Schulman, B.R., Esquela-Kerscher, A., and Slack, F.J. 2005. Reciprocal expression of lin-41 and the microRNAs let-7 and mir-125 during mouse embryogenesis. Dev. Dyn. 234: 1046-1054.

Shi, R. and Chiang, V.L. 2005. Facile means for quantifying microRNA expression by real-time PCR. Biotechniques 39: 519-525.

Suh, M.R., Lee, Y., Kim, J.Y., Kim, S.K., Moon, S.H., Lee, J.Y., Cha, K.Y., Chung, H.M., Yoon, H.S., Moon, S.Y., et al. 2004. Human embryonic stem cells express a unique set of microRNAs. Dev. Biol. 270: 488498.

Takamizawa, J., Konishi, H., Yanagisawa, K., Tomida, S., Osada, H., Endoh, H., Harano, T., Yatabe, Y., Nagino, M., Nimura, Y., et al. 2004. Reduced expression of the let-7 microRNAs in human lung cancers in association with shortened postoperative survival. Cancer Res. 64: 3753-3756.

Thomson, J.M., Parker, J., Perou, C.M., and Hammond, S.M. 2004. A custom microarray platform for analysis of microRNA gene expression. Nat. Methods 1: 47-53.

Wienholds, E. and Plasterk, R.H. 2005. MicroRNA function in animal development. FEBS Lett. 579: 5911-5922.

Wienholds, E., Kloosterman, W.P., Miska, E., Alvarez-Saavedra, E., Be- rezikov, E., de Bruijn, E., Horvitz, H.R., Kauppinen, S., and Plasterk, R.H. 2005. MicroRNA expression in zebrafish embryonic development. Science 309: 310-311.

Wightman, B., Ha, I., and Ruvkun, G. 1993. Posttranscriptional regulation of the heterochronic gene lin-14 by lin-4 mediates temporal pattern formation in C. elegans. Cell 75: 855-862.

Yang, W., Chendrimada, T.P., Wang, Q., Higuchi, M., Seeburg, P.H., Shiekhattar, R., and Nishikura, K. 2006. Modulation of microRNA processing and expression through RNA editing by ADAR deaminases. Nat. Struct. Mol. Biol. 13: 13-21.

Zhao, Y., Samal, E., and Srivastava, D. 2005. Serum response factor regulates a muscle-specific microRNA that targets Hand2 during cardiogenesis. Nature 436: 214-220. 


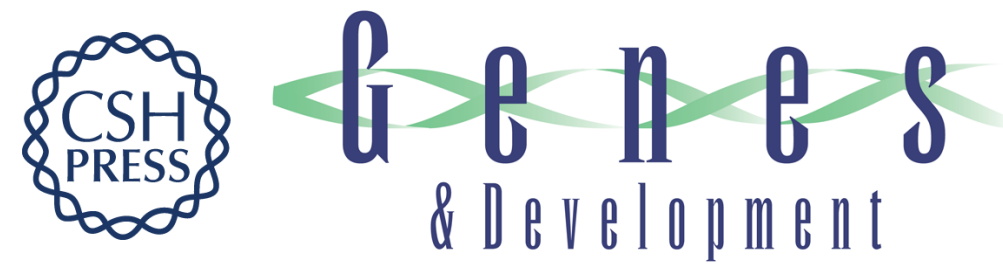

\section{Extensive post-transcriptional regulation of microRNAs and its implications for cancer}

J. Michael Thomson, Martin Newman, Joel S. Parker, et al.

Genes Dev. 2006, 20:

Access the most recent version at doi:10.1101/gad.1444406

\section{Supplemental http://genesdev.cshlp.org/content/suppl/2007/11/21/gad.1444406.DC1 Material}

Related Content Regulating the Regulator

Sci. STKE August, 2006 2006: tw285

References This article cites 33 articles, 10 of which can be accessed free at: http://genesdev.cshlp.org/content/20/16/2202.full.html\#ref-list-1

Articles cited in:

http://genesdev.cshlp.org/content/20/16/2202.full.html\#related-urls

\section{License}

Email Alerting

Receive free email alerts when new articles cite this article - sign up in the box at the top Service right corner of the article or click here.

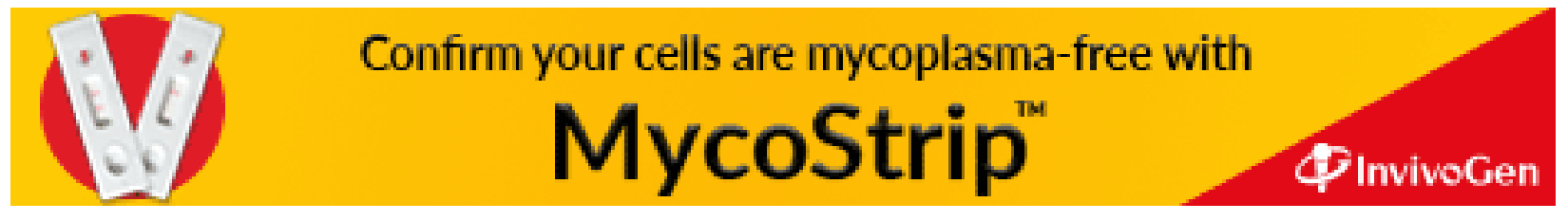

